\title{
MODELLING AS A KNOWLEDGE GAINING TECHNIQUE FOR PRIMARY SCHOOL STUDENTS WHO LEARN SOLVING COMPLEX TASKS
}

\author{
Aleksandra Makarova, $\mathrm{PhD}$ in Philosophy, \\ and Sergey Musiychuk, PhD in Philosophy, \\ NMSTU,Magnitogorsk, Russia. \\ AdemirDamazio, PhD \\ UNESC, Criciuma, Brazil
}

\begin{abstract}
Using an example of composite tasks and the teaching technique behind them, the authors describe how primary school students learn to use modelling as part of their knowledge gaining process in education. The use of modelling during math classes is one of the pre-conditions for successful learning with primary school children as with the help of modelling children can better imagine what the task implies and better understand the relationship between different values, which enhances their awareness when deciding on what operation to apply, and so on.

The article describes different models and submodels used by teachers for task modelling. It is noted that when learning how to solve composite tasks, children learn to reflect and acquire the ability to act inside their minds and analyze their thinking.
\end{abstract}

Keywords: Knowledge gaining, mathematics teaching, modelling, composite task.

The problem of using modelling as a method of gaining knowledge when teaching primary school students how to solve composite math tasks appears to be one of the most critical areas of today's instruction. Modelling has become one of the main methods of scientific research which is applied everywhere, by all disciplines and at all stages of research. Modelling helps break down a complex issue into simpler components. It helps see and feel something one otherwise cannot see or feel. It turns something one has never dealt with before into recognizable forms. In other words, modelling helps make a complex reality accessible for thorough and comprehensive 
examination. Different approaches can be used to justify the need for junior schoolchildren to learn how to use modelling for knowledge gaining.

Firstly, the concepts of models and modelling when introduced in the instructional process make learners change the way they perceivea subject of the curriculum by increasing their awareness and performance.Secondly, when junior children are consistently trained to use modelling, it brings them closer to the knowledge gaining techniques while developing their minds. Thirdly, the ability of children to handle problem solving situations is an indicator of how trained and educated they are. Learning how to solve tasks is considered the most difficult part in any field of study, and the difficulty here is usually not about calculations one has to do (i.e. the technical aspect of a task) but it is rather related to the analysis one has to undertake prior to finding an appropriate solution (i.e. the approach). Modelling serves as one of the most efficient techniques that help overcome such difficulty.

Therefore, most scholars believe that the use of modelling in teaching plays an increasingly important role in the development of theory of instruction both as a discipline and a profession.

The necessity of using modelling in instruction was pointed out by such psychologists as V. I. Zagvyazinskiy (14), V. V. Davydov (3), L. V. Zankov (15) and others. According to A. V. Beloshistaya (2), modeling serves as the basis for one of the problem solvingmethods. As L. A. Krivtcova (7) points out, "pictures, diagrams and drawings not only help learners to mindfully identify unobvious relationships between values".

D. S. Fonin and I. I. Tcelishcheva (1990) believe that modelling is the key to developing mathematical thinking and they use models of tasks when teaching students how to solve tasks. M. A. Matveeva (2002) shares this view.

For modelling to work as a means of gaining knowledge, the teacher should not only introducevarious models to his/her students whiledemonstrating how to build models of certain phenomena. The teacher should rather have the students build models and rely on models when exploring certain objects or phenomena.

Although almost all primary school programmes include modelling as one of the major methods of teaching and learning, schoolchildren still find it difficult to build models. Whereas there seems to be almost no problem with modelling objects or 
processes, many children struggle to build models when it comes to abstract ideas. We believe that one of the reasons for this is that that stage of learning involves most of the cognitive processes, such as perception, attention, reflection, retention and imagination. If one of the processes happens to be underdeveloped, this may impact the child's modeling skills.K.D. Ushinsky emphasized on the importance of "mental emotions like amazement, curiosity, sadness, joy, and other such feelings" (Guseva, 2017).

Model,from the Latin 'modulus', i.e. measure or pattern, is an analogue of an object, process or situation that is built following certain rules and that shows all the relationships inside the object of interest so that it was possible to learn something new about the object by studying its analogue. Accordingly, modelling may be defined as a way of building a model(Beloshistaya, 2003).Thus, not only lines or groups of lines but also multi-colour stripes can be used for modelling ones and tens.
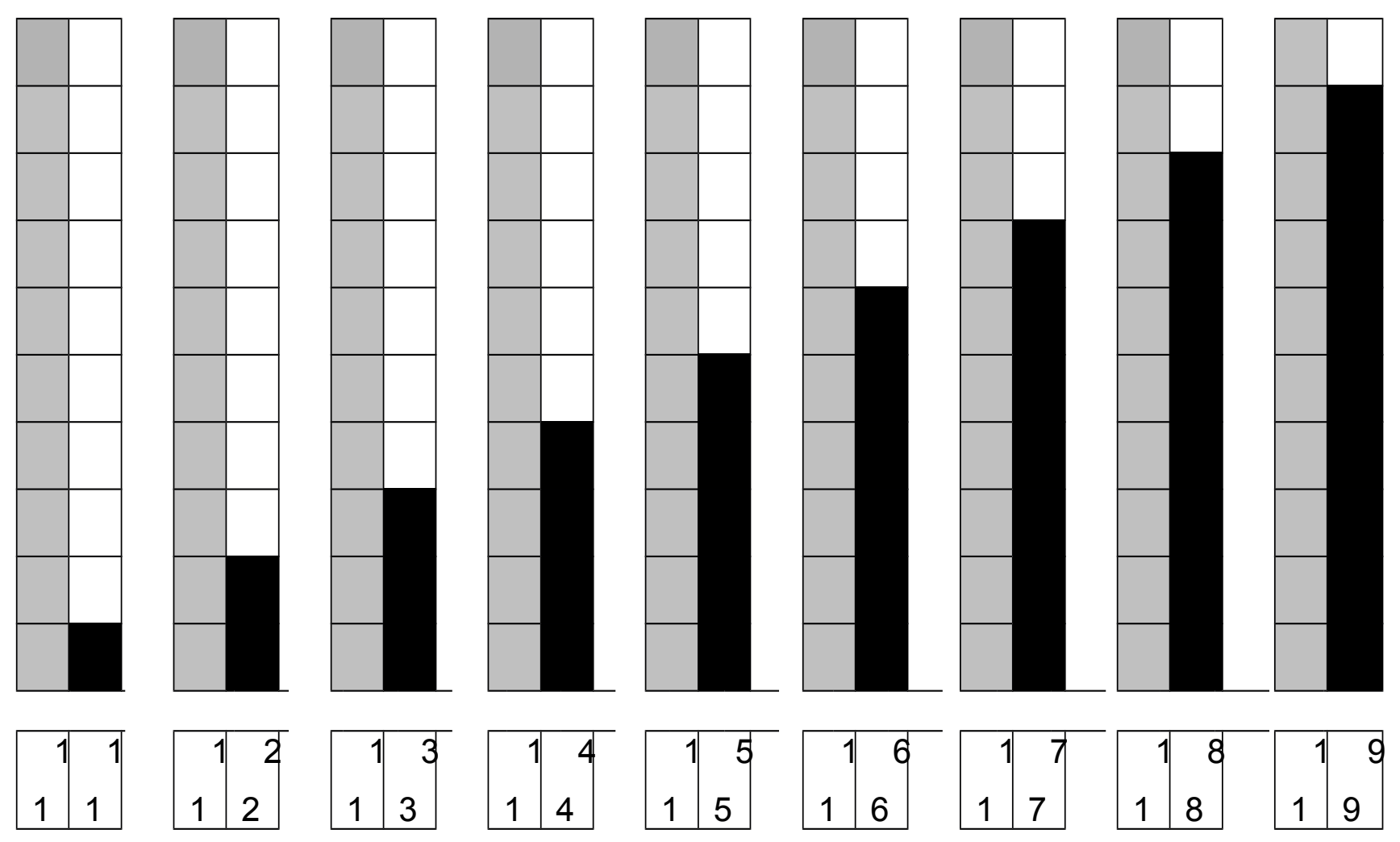

When teaching about hundreds and how to call round hundreds, a plate comprising 100 blocks is used as a model of a hundred.

Task modelling has been thoroughly studied by N. G. Salamatova, who points out the following actions which build the modelling process: 1 . Analysis of the material (text) to be modelled, i.e. identification of key meaningful elements and their relationship, 
which shall further be presented with the help of symbols. 2. Translation of the text into the language of symbols while ensuring strict correspondence between the elements of the original text and the elements of the resultant model. Otherwise the model will fail to properly represent the phenomenon concerned. 3. Children should be able to apply the same set of symbols for similar relationships and elements and to use different symbols for different elements and relationships. Naturally, this only refers to one model, or one task. 4. Transformation of the model. With this actionthe students can rearrange the elements of the model and so on. 5. Comparison of the model with the reality. This helps learn more about the object or phenomenon concerned. The above actions represent the objectives of modeling (Salamatova, 2004).

The following principles must also be observed when building a model:

1) A model should reflectspecial (in this case, quantitative) relationshipsof the reality; 2) A model can and should substitute the corresponding objects, phenomena or processes of reality it is meant to represent; 3) A model, while representing the structure of an object, process, situation, etc., should serve a good substitution so that one could learn more about such object, process or situation.

The mathematical modelling tools include symbols, signs, pictures, drawings and diagrams.

All models are generally divided into schematizedand symbolic models. Schematized models are further broken into material models(they enable to produce physical effects on objects) and graphical models(they produce graphical effects). Symbolic models can be built using either natural or mathematical language. Natural models include tables and shorthand notations. Mathematical models are expressions and solution notations. Graphical models can be pictures (they can be pictures of real objects), symbolic pictures(symbolic representation of objects with the help of figures), drawings (symbolic representation of objects showing the relationships between them and the correlation of values with the help of links and a certain scale) and schematics (drawings with no scaling accuracy).

It makes sense to use drawings when solving tasks involving given values and a target value when one knows how they relate to each other (more than, less than, or equal to), as well as when solving motion related problems. A link illustrates thedistance travelled by a body in motion; an arrow shows the direction of motion; a flag or a column 
indicates a point in the moving body's route with the speed indicated above or beneath the arrow and the time indicated above the distance link. A drawing clearly shows the relationship between different values and when used for motion problem solving, the drawing provides a graphical presentation of a given problem.

Table is another model, which is more abstract compared with a sketch or a drawing. Tables are used when learners are well familiar with how different values correlate with one another as tables do not show such relationships. When children are introduced to such tasks for the first time, tables may help them imagine what the problem implies and choose the right operation.

When dealing with composite tasks, a schematic illustration, i.e. shorthand notation, is used together with the graphical presentation. A shorthand notation includes values, given and target numbers, as well as certain wording describing the problem, such as 'there was/were', 'there was/were added', 'resulted in' and so on, and such terms as 'more', 'less', 'equal', etc.

Consequently, for children to better imagine a problem, grasp how different values correlate with one another and exercise better awarenesswhen deciding on what operation to apply, they should be consistently trained to use modelling. Children should first be taught to illustrate the relationship between objects expressed as numbers while showing the underlying action. After that they should be introduced to more general graphical modelling techniques, i.e. shorthand notation, with a drawing or a sketch created as the children are watching or with the children actually participating. This may be followed with the introduction of ready-made aggregate diagrams and tables offering a higher degree of abstraction.

As an example we shall consider the technique of applying shorthand notations for composite task solving offered by S. N. Lysenkova (Lysenkova, 1988).

One shelf houses 5 books, the other shelf houses 2 books more. How many books are there on the two shelves?

The teacher follows the student's thinking process and puts the following on the board:

Shelf I - 5 books

Shelf II - X, 2 books more 
- How do you interpret '2 books more'? (If it is the same amount of books as there is on the first shelf or it is 2 extra books).

Shall we analyze the task?- Look at the question of the task.

- Are we going to be able to answer the question right away?

- Why not? (Because we do not know how many books there are on the other shelf).Correct.

- How many operations does the task take? What task shall we try to solve?

One student has the following considerations: "We know that there are two books more on the second shelf than on the first. How many books are there on the second shelf if there are 5 books on the first? We can count how many books there are on the other shelf. I put: $5+2$ ".

We shall add an intermediate operation to the task presentation scheme. This is how it will look now:

Shelf I - 5 books

Shelf II -2 books more $\quad(5+2) ?$

Having compared it with the previous notation we find a new line, i.e. $5+2$.

- Whyadding? - The target number is $\square$ more, so I add.

The second student describes the next operation: "Now we know that one shelf has 5 books and the other one has $(5+2)$ books. We can count how many books there are on the two shelves together. Iput: $5+(5+2)=12$."

- Whyadding?

- I need to find out the total number of books on the shelves, so I add.

The third student gives the answer to the question: "I put the answer: There are 12 books on the two shelves".

It should be noted that the use of intermediate operations within shorthand notations can be helpful when teaching students to build expressions when dealing with composite tasks. The children's personal traits should also be considered when teaching students to apply modelling to composite tasks. L. A. Krivtcova, a primary school teacher (Linevo village,Novosibirsk Region), gives the following recommendations: 
1. Children in a class usually have different modelling skills. That is why children should be given freedom to use such modelling techniques that will work best for them. For children with inferior modelling skills, it could mean handling real objects or their substitutes.

2. The aim of teaching is to create a situation of success for every student. Success is the only motivation for a child that gives him/her courage to embrace a challenge.

3. When planning a lesson, the teacher should remember that children are all different and may need different approaches. For example, visuals should be offered written tasks as such children learn through visual perception. At the same time auditives learn when they listen, so when teaching such children how to solve tasks with the help of models the teacher should ask them to work in pairs, i.e. apply role play. Auditives need to be constantly engaged in dialogues.

4. Who suffers most of all at school are kinesthetic learners. Classrooms are usually not designed for that level of physical activity or noise that they need. Such children just cannot be quiet. That is why work groups with rotating members, games and competitions should be introduced for such learners. Real objects and experiments should be applied when teaching kinesthetic learners to solve tasks (Krivtcova, 2002).

Further, we shall consider modelling as a method applied in a mathematics class for junior schoolchildren, in particular when teaching about composite tasks. For example, A. V. Beloshistaya believes that modeling can be a useful method applied at the stage preceding the introduction of tasks, as well as when teaching to solve both simple and composite tasks. Modelling facilitates in understanding a task. A child who was trained to apply modelling as the basic approach to solving tasks sees problem solving as a process of translation of one model into another model which has the same structure but a different description. The child can then easily apply this approach when solving various types of problems (Beloshistaya, 2003).

As the teacher N. A. Matveeva points out, one can use a schematic to illustrate a task, which provides a transition from the text of the task to the choice of an arithmetic operation and the creation of a mathematical model. Such model helps develop a student's ability to explain his/her reasoning behind finding a solution to the problem. 
During the introduction of schematics as part of the composite task modelling N. A Matveeva follows the following approach: a) the teacher explains about every part of the model; b) the teacher provides advice on how to build a model; c) students are building a model guided by the teacher's questions while the teacher, or the students, is drawing a resultant schematic on the board or while the teacher is drawing a schematic on the board and the students are doing the same in their workbooks.

Once the schematic is ready, the students use it to go through the task again while explaining every number and every question of the task. The resulting schematic clearly shows the numbers, the problem, and their relationship (Matveeva, 2002).

S. E. Tsareva points out another aspect of modelling when it is applied to solving tasks. She uses modelling a lot when working with a problem that has been solved. The author proposes the following steps:

1. Identifying how the contents of a task correspond with the schematic (the drawing, the table, or other) and vice versa.Example tasks: Does this schematic match the task? What should you change in the schematic to make it match the task? 2. Choosing a schematic, out of given schematics (drawings, tables, shorthand notations), that matches the task.3. Choosing a task, out of tasks given on a textbook page, on the board, on a card, etc., that matches the schematic (the drawing, the table, or the shorthand notation).4. Finding mistakes in the schematic, drawing, table, etc, built for the given task.

The purpose of the above steps is to help develop the ability to apply different models in search of the solution to a task as the application of such models makes it necessary to explain how the task relates to the schematic, the drawing, the table, etc. (Tsareva, 1990).

When dealing with composite tasks during math classes, S. N. Lysenkova tries to develop the students' mathematical thinking by making students formulate reverse problems (Lysenkova, 1988). This technique helps identify the relationships within a task making it a successful learning practice. Belowisanexample.

Directproblem. On the first day they gathered 20 baskets of apples, on the second day they gathered 30 baskets more than on the first day. On the third day they gathered 5 baskets less than on the second day. How many baskets of apples were gathered on the third day? 


\section{CRIAR EDUCAÇÃO}

Revista do Programa de Pós-Graduação em Educação - UNESC
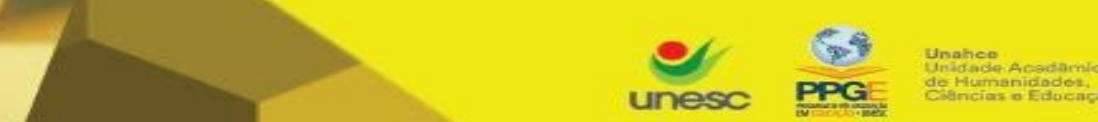

S. N. Lysenkova suggests that the following numbers should be singled out: 20 , 30 more, 5 less. The numbers should then be arranged in a scheme showing how they relate to each other.

After the problem has been analysed based on the scheme and the direction of arrows has been determined, the students should write down the solution.

1) $20+30=50$ (b.)

2) $50-5=45$ (b.)

After that the students are offered to use the scheme and formulate reverse problems by playing with the arrows. The benefit of such exercise is that the same number, concept or value participates in a number of different relationships, and such exercise helps efficiently build problem solving skills with junior schoolchildren.

An analysis of the instructional literature indicates that modelling, when used for solving composite tasks, is extensively adopted by instructional designers and teachers. The authors point out the importance of modelling and highlight different application aspects to make it a successful teaching and learning experience in the case of junior children learning to solve tasks.

The use of modelling in primary school mathematics training is one of the prerequisites for successful learning. Modelling helps students better imagine the situation implied in a task, figure out how different values correlate with each other, exercise better awareness when deciding on what operation they should apply and so on. Within the realm of instructional literature, a model is interpreted as an analogue of an object, process or situation that reflects all the relationships inside such object and

Criar Educação, Criciúma, v. 6, n², julho/novembro 2017.- PPGE - UNESC 
should be able to serve as a substitute enabling to learn something new about the object by studying its analogue. In the context of this study, modelling is interpreted as a way of building a model.

We rely on the following classification of models. All models are divided into schematized and symbolic models. Schematized models are further broken into material models, which enable to produce physical effects on objects, and graphical models, which provide graphical effects. Symbolic models can be built using either natural or mathematical language. Natural models include tables and shorthand notations whereas mathematical models are expressions and solution notations. Graphical models can be pictures, symbolic pictures, drawings and schematics.

When analysing literature on psychology and instruction, one may conclude that when learning to deal with composite tasks children learn to reflect and acquire the ability to act inside their minds and analyse their thinking. This helps develop students' logical reasoning as students have toapply such operations as analysis, synthesis, comparison, classification and generalization. Having students deal with problem solving situations supports the teacher in realising instructional, educational and developmental objectives. Such problems help bring theory and practice together, to integrate learning with practical experience.Dealing with such problems helps expand and enrich students' views and perceptions and build practical skills (e.g. calculating the cost of an item or a service) and so on.

The analysis of instructional literature suggests that modelling is extensively adopted by instructional designers and teachers. The authors point out the relevance of modelling in mathematics training, especially when dealing with tasks. A child who was trained to apply modelling as the basic approach to solving tasks sees problem solving as a process of translation of one model into another model which has the same structure but a different description. The child can then easily apply this approach when solving various types of problems.

One may conclude that modelling, when it is used as a knowledge gaining technique in primary school education (alongside with analysis, synthesis, induction, etc.), serves as a hugely efficient method of developing children's minds in general and mathematical thinking in particular. Modellinghelpsmaketheprocessofinstructionlessverbal. 
Ithelpsvisualizetheobjectofstudyandexploreallthemathematicalrelationshipsandpatterns.

Modelling, when applied in mathematics training (in particular when teaching about composite tasks), not only makes it easier to find solutions, but it also triggers such cognitive processes as perception, reflection, imagination, which helps shape a child's views of the world. In this respect, the approach described above can be compared with other psychological theories and educational methods, most notably with the system of developmental education of L. V. Zankov (Arginskaya,1991; Zankov, 1977). The Zankov system is based on the innate desire of a child to explore and to learn. "..children are fond of enquiry and analytical activities. Within the Zankovian system learners are encouraged to freely proffer observations about the material being studied. The teacher's role is to draw pupils' attention to the obvious patterns and connections in the subject matter and require that they deduce and explain the nature of those relationships" (Guseva\&Sosnowski, 1997). A child, motivated by astonishment, follows a natural path of an explorer or researcher and gains not only the knowledge but also important skills of the self-study that will underly his/her success in the secondary and high school.

When analysing the instructional literature we noticed that modelling is more or less popular with all the authors who are engaged in the development of primary education programmes. Modelling is also mentioned in the State Higher Professional Education Standard applicable to the following primary school teacher training course: Instruction and Design in Primary School Education. Many instructional designers and teachers venture outside of the established system and engage in the development of their own approaches that use modelling for mathematics teaching, which attests to the important role of modelling in education.

\section{References:}

1. Arginskaya, I. I.ObuchaemposistemeL.V.Zankova. Knigadlyauchitelyal.I.Arginskaya, N.Ya.Dmitrieva, A.V.Polyakova, M.:Prosveshchenie, 1991. 240 p.

2. Beloshistaya, A. Obuchenieresheniyuzadach $v$ nachalnoishkole.Knigadlyauchitelya. A.V.Beloshistaya, M.:Russkoeslovo, 2003. 288 p. 
Osnovymetodologii,metodikiitekhnologiipedagogicheskogoissledovaniya.

Davydov, V. V. metodicheskoeposobie. / V.V.Davydov, M.:Akademiya, 1997. 138 p.

4.

Fonin, D. S.

Modelirovaniekakvazhnoesredstvoobucheniyaresheniyuzadach.D.S.Fonin,

I. I. Tcelishcheva. Elementary school. 1990. - № 3, p. 33.

5. Guseva, L. G., Sosnowski, A. N. Russian Education in Transition: trends at the primary level // Canadian and International Education. 1997, v. 26. - № 1, p. 14-31. URL: http://ir.lib.uwo.ca/cie-eci/vol26/iss1/3 (accessed 15.01.2017).

6.Guseva, L. G.History of education: moral and spiritual education / Pedagogical science - 2017. - № 4. - p. 28-31.

http://pedagogy.science-review.ru/pdf/2017/2017_4.pdf (30.04.2017)

$7 . \quad$ Krivtcova, L. A.

$\mathrm{K}$

voprosu

0

formirovaniideistviyamodelirovaniyanaurokakhmatematiki $\quad \mathrm{V}$ nachalnoishkole. L.A.Krivtcova // Sibirskiyuchitel. 2002. - № 5, p. 17-19.

8. Lysenkova, S. N. Metodomoperezhayushchegoobucheniya. Knigadlyauchitelya. Izopytaraboty. S.N.Lysenkova. M. Prosveshchenie, 1988. 192 p.

9. Matveeva, N. A. Ispolzovanieskhematicheskogochertezha v modelirovaniiprostykhtekstovykhzadach. N.A.Matveeva// Elementary school. 2002. № $10 . \quad$-p. 60-63. URL: $\quad$ http://n-shkola.ru/storage/archive/1407240979942352518.pdf(accessed 15.01.2017).

10. Matveeva, N. A. Kombinirovannayavspomogatelnaya model zadachi. N.A.Matveeva // Elementary school plus Before and After. 2002. - № 1,p. 68-69.

Salamatova, G. I.

Voobrazheniekakkomponenttvorchestvapriizucheniimatematiki.G.I.Salamatova // Eleme ntary school plus Before and After. 2004. -№ 9,p. 21-24.

12. Tcareva, S. E. Vidyraboty $\mathrm{S}$ zadachaminaurokahmatematiki.

S.E.Tcareva // Nachalnayashkola. 1990. - № 10,p. 37-41.

13. Vygotsky, L. S. Educational psychology. CRC Press, 1997. 416 p.

14.

Zagvyazinsky, V. I.

Metodologiyaimetodypsikhologo-

pedagogicheskogoissledovaniya.V.I.Zagvyazinskiy, R.A.Atakhanov, M.:Akademiya, 2001. $178 \mathrm{p}$.

Criar Educação, Criciúma, v. 6, n², julho/novembro 2017.- PPGE - UNESC 
15.Zankov, L. V. Teaching and development. White Plains, NY : M.E. Sharpe, 1977. 292 p.

About authors:

\section{Makarova Aleksandra Konstantinovna}

$\mathrm{PhD}$ in Philosophy, Director of Library Complex at Nosov Magnitogorsk State Technical University

\section{Musiychuk Sergey Vasilyevich}

PhD in Philosophy, Assistant Professor, State and Municipal Administration and HR Management Department, Nosov Magnitogorsk State Technical University

AdemirDamazio, UNESC, Criciuma, Brazil 